\title{
Vesico-Vaginal Fistula Repair by a Vaginal Approach
}

\author{
Jorrit Colenbrander $^{\mathrm{a}} \quad$ John Heesakkers $^{\mathrm{b}} \quad$ Frank Martens $^{\mathrm{a}}$ \\ aDepartment of Urology, Radboudumc, Nijmegen, The Netherlands; ${ }^{\mathrm{b}}$ Department of Urology, MUMC+, \\ Maastricht, The Netherlands
}

\section{Keywords}

Urology · Urologic surgical procedures · Vesico-vaginal fistula

\begin{abstract}
Introduction: The aim of this study is to determine the outcome of surgically treated vesico-vaginal fistulae (VVaFs) using a transvaginal approach with a Latzko technique. Methods: A retrospective chart study was conducted at the Department of Urology, Radboud University Medical Centre. Surgical approaches to repair VVaF, from 2014 to September 2020, were selected. Patients who underwent a transvaginal approach were included. The primary objective was fistula closure. Secondary objectives were predictive factors for the outcome of the surgical procedure, for example, patient characteristics, leakage on cystography 2 weeks postoperative, and surgery time. Results: Thirty-one patients had surgery for VVaF. Twenty-five procedures (81\%) were performed transvaginally. Thirteen of these (52\%) had successful transvaginal closure after the first attempt. Seven out of 12 had their second attempt at the time of analysis, of which 4 (57\%) were successfully closed thereafter. After either 1 or 2 attempts with the transvaginal approach, 17 (68\%) of the
\end{abstract}

VaFs were successfully closed, but $79 \%$ if patients who did not yet had a second attempt were taken into account with the current success extrapolated. Only few minor complications were observed. Conclusion: Transvaginal closure of VaFs with a Latzko technique is successful in about $79 \%$ in either 1 or 2 attempts, with few minor complications. A second attempt in closing the fistula with a transvaginal approach is useful, and a previous transvaginal attempt is not a contraindication for a second transvaginal attempt in closing the VVaF surgically.

(C) 2021 The Author(s)

Published by S. Karger AG, Basel

\section{Introduction}

\section{Background}

A vesico-vaginal fistula ( $\mathrm{VVaF}$ ) is an abnormal communication between the bladder and the vagina, which results in urinary incontinence and repeated urinary tract infections [1]. VVaFs in Western countries are relatively rare. Most of the $\mathrm{VVaFs}(83.2 \%)$ are caused by previous pelvic surgery, mainly due to hysterectomy [2]. Other causes of VVaFs are malignant disease, radiotherapy, or obstetric trauma. Obstetric trauma is a more common

C 2021 The Author(s).

Published by S. Karger AG, Basel

This is an Open Access article licensed under the Creative Common Attribution-NonCommercial-4.0 International License (CC BY-NC) (http://www.karger.com/Services/OpenAccessLicense), applicable to the online version of the article only. Usage and distribution for commercial purposes requires written permission.
Correspondence to:

Jorrit Colenbrander, jorrit.colenbrander@ radboudumc.nl 
cause of VVaFs (95.2\%) in third-world countries, due to prolonged neglected obstructed labor $[2,3]$.

VVaFs cause significant morbidity and have a severe impact on patients' mental health because of permanent leakage of urine [4]. In few cases, $\mathrm{VVaFs}$ can be treated conservatively, but not every $\mathrm{VVaF}$ is suitable for this. Most conservative methods have a reported success rate between $3 \%$ and $100 \%$ [5]. This variation in result indicates that in a large group of patients, conservative treatment will not be successful in clinical practice. When conservative treatment fails, the next step is surgical intervention.

The main surgical intervention of VVaFs in this study is the transvaginal approach with a Latzko technique. This is a transvaginal approach with circumferential incision around the $\mathrm{VVaF}$ with mobilization of 2 layers of the bladder and vaginal wall. This is an important step to enable tension-free closure. The fistula tract is closed using inverting sutures at the bladder. To confirm successful closure of the fistula tract, the methylene blue test is performed. The vaginal wall is closed using everting sutures square to the underlying suture line at the bladder site.

\section{Aim of the Study}

This study aims to determine the outcome of surgically treated VVaFs using a transvaginal approach with a Latzko technique.

\section{Materials and Methods}

\section{Study Design and Setting}

A retrospective chart study of patients with a $\mathrm{VVaF}$ was conducted at the Department of Urology, Radboud University Medical Centre.

\section{Study Subjects}

Patients presenting with $\mathrm{VVaF}$ who underwent a surgical transvaginal procedure, from 2014 to September 2020, were selected for possible inclusion in this study. Patients with other fistulae (e.g., urethro-vaginal fistula) were excluded from this study, as well as patients who primarily underwent a urinary diversion procedure instead of closure of the fistula. Only patients with a follow-up of at least 3 months after the first attempt were included.

\section{Methods and Measurements}

This is a retrospective chart study. Patient characteristics were noted along with comorbidity/risk factors like smoking, diabetes, or preoperative irradiation and a medical history. The primary outcomes were a closed fistula shown on cystography 2 weeks after surgery, the experience of normal voiding and urinary continence 6 weeks after surgery, and the event of a persistent or recurrent $\mathrm{VVaF}$.

The catheter placed during surgery remained in situ for an extended period of time in case of leakage shown on cystography 2
Table 1. Patient characteristics

\begin{tabular}{|c|c|c|}
\hline & $n$ & $(\%)$ \\
\hline Patients, $N$ & 31 & \\
\hline \multicolumn{3}{|l|}{ Age, years } \\
\hline Mean & $55.0 \pm 15.6$ & \\
\hline Median & 53.0 & \\
\hline Range & $28-89$ & \\
\hline \multicolumn{3}{|l|}{$\mathrm{BMI}, \mathrm{kg} / \mathrm{m}^{2}$} \\
\hline Mean & $27.2 \pm 6.0$ & \\
\hline Range & $19.9-43.9$ & \\
\hline \multicolumn{3}{|l|}{ Etiology } \\
\hline Uterus extirpation & 18 & (58) \\
\hline Pelvic surgery & 9 & (29) \\
\hline Obstetric trauma & 1 & (3) \\
\hline Others ${ }^{1}$ & 3 & (10) \\
\hline \multicolumn{3}{|l|}{ Comorbidity } \\
\hline Diabetes mellitus & 6 & (19) \\
\hline Hypertension & 7 & (23) \\
\hline Stroke & 3 & (10) \\
\hline COPD/asthma & 3 & (10) \\
\hline Others $^{2}$ & 5 & (16) \\
\hline
\end{tabular}

${ }^{1}$ Others include radiotherapy induced and foreign body (pessary). ${ }^{2}$ Others include hypothyroidy, rheumatoid arthritis, fibromyalgia, and Crohn's disease.

weeks after operation. Patients with leakage shown on cystography were compared with patients without leakage to evaluate the effect of an extended period of the indwelling catheter.

A timeline was created including etiology, onset of complaints, surgical operation, and follow-up. The date of the VVaF operation was noted along with the identity of the urologist and the duration of the procedure to reveal a possible surgical learning curve for this specific operation. Patients were followed for at least 3 months after the operation, with a further follow-up in case of unresolved complaints.

\section{Data Analysis}

Data were analyzed using SPSS. Descriptive statistics were used to analyze the outcome of the procedures. A possible association of (predictive) parameters toward the recurrence of a $\mathrm{VVaF}$ was analyzed using logistic regression.

\section{Results}

Thirty-one patients had surgery for VVaF. The most common cause of the $\mathrm{VVaF}$ in this cohort was a hysterectomy (abdominal or vaginal), which composed $58 \%$ of the VVaF etiology (shown in Table 1). Other pelvic surgery performed accounted for $29 \%$ of the $\mathrm{VVaF}$ etiology. Other etiologies (13\%) were obstetric trauma, radiotherapy, and 1 pessary eroding into the bladder. 
Table 2. Outcome of $\mathrm{VaF}$ operation using a transvaginal approach with a Latzko technique, in the first and second attempt

\begin{tabular}{lll}
\hline & \multicolumn{1}{l}{ Attempt No. } \\
\cline { 2 - 3 } & $\begin{array}{l}1 \text { st } \\
(n=25)\end{array}$ & $\begin{array}{l}\text { 2nd } \\
(n=7)\end{array}$ \\
\hline $\begin{array}{c}\text { Cystography*, } n \text { (\%) } \\
\text { No leakage (closed) }\end{array}$ & $21(84)$ & $5(71)$ \\
$\begin{array}{c}\text { Patient experience**, } n(\%) \\
\quad \text { Intact urinary continence } \\
\text { Normal voiding }\end{array}$ & $16(64)$ & $5(71)$ \\
$\begin{array}{l}\text { Recurrent VVaF, } n(\%) \\
\text { Recurrence }\end{array}$ & $18(72)$ & $6(86)$ \\
\hline
\end{tabular}

VVaF, vesico-vaginal fistula. ${ }^{*}$ Control cystography performed 2 weeks after operation. ** Patient experience 6 weeks after operation.

Eighty-one percent of the VVaF repairs were of a transvaginal approach $(n=25)$. Among the patients included in the transvaginal group, persistence or recurrence of the fistula was noted in $12(48 \%)$ patients (shown in Table 2). Of the patients with a fistula recurrence who had undergone a second attempt in closing the fistula ( $n$ $=7$ ), the transvaginal approach had $4(43 \%)$ recurrent fistulae (shown in Table 2). After 1 or 2 attempts with the transvaginal approach, 17 (68\%) of the VVaFs were successfully closed. The success rate of the transvaginal approach was $52 \%$ in the first attempt and $57 \%$ for the 7 patients who underwent a second attempt. Five patients with a recurrent fistula did not undergo a second transvaginal attempt in closing the fistula within this study.

Five patients with leakage shown on cystography 2 weeks after surgery had a catheter in situ for an extended period of time. All 5 patients with a persisting fistula on cystography continued to have a $\mathrm{VVaF}$, independent whether or not the catheter remained in situ for an extended period of time. Although the catheter was not removed for this extended period, the VVaF remained in all 5 patients.

Ten patients with a closed fistula shown on cystography 2 weeks after the procedure did eventually develop a recurrent fistula. The duration for the onset of complaints of a recurrent fistula, in patients with a former closed fistula shown on cystography, is median 117 days (range 55-127, with 1 up to 284 days).

The surgical closure of VVaFs within this study showed only minor complications (shown in Table 3 ). The most common complication $(n=4)$ was the occurrence of a urinary tract infection. Stress incontinence occurred in 2 patients after the transvaginal procedure.

Vesico-Vaginal Fistula Repair
Table 3. Complications of VVaF operations

\begin{tabular}{ll}
\hline Complications & $\begin{array}{l}\text { Transvaginal } \\
(n=32)\end{array}$ \\
\hline Urinary tract infection & 4 \\
Stress incontinence & 2 \\
Wound infection & 1 \\
Thrombosis (DVT) & 0 \\
\hline \multicolumn{1}{c}{ VVaF, vesico-vaginal fistula. } & \\
\hline
\end{tabular}

When predictive factors were analyzed (shown in Table 4), we found that within the group of patients who were in need of a second attempt in closing the fistula and thus had a persistent or recurrent fistula, 4 (33\%) were former smokers or actual smokers. There was no significant difference in the group of patients with no recurrence, where $4(31 \%)$ of the patients were former or actual smokers.

One of the predicting parameters for success was a previous repair of a $\mathrm{VVaF}$ elsewhere, before being admitted to our hospital. Of the patients in this study with an unsuccessful closure, 3 (25\%) underwent previous VVaF surgery elsewhere. Within the group of patients with successful closure of the VVaF, 6 (46\%) already underwent a previous attempt in closing the $\mathrm{VVaF}$ elsewhere.

There was no surgical learning curve with a decrease in duration of procedures or in recurrence rate over time (shown in Fig. 1). When comparing the duration of the procedures and the outcome of the procedures over time, we observed for the first and, respectively, the last 10 operations a success rate of both $40 \%$ and a mean duration of 87 and $98 \mathrm{~min}$, respectively. When comparing the duration to the outcome of the procedures, we observed a median duration of $86 \mathrm{~min}$ (range 44-207) in patients with a recurrent $\mathrm{VVaF}$ and a median duration of $83 \mathrm{~min}$ (range 49-142) in patients with no recurrent VVaF.

\section{Discussion and Conclusion}

We analyzed the outcome of vaginal approach of VVaFs. This approach is often chosen because it is minimally invasive with minimal morbidity. In this study, not all recurrent fistulae underwent a second attempt in closing the fistula. The accumulated success of the transvaginal approach is $79 \%$ taking 1 or 2 attempts into account to fully close the VVaF. This accumulated success is an extrapolation of the current success rates of the patients 
Table 4. Risk factors for a recurrent fistula in the first and second attempt

\begin{tabular}{|c|c|c|c|c|}
\hline & \multicolumn{4}{|c|}{ Attempt No. } \\
\hline & \multicolumn{2}{|c|}{ Recurrent VVaF } & \multicolumn{2}{|c|}{ No recurrent $\mathrm{VVaF}$} \\
\hline & $\begin{array}{l}1 \mathrm{st} \\
(n=12)\end{array}$ & $\begin{array}{l}2 n d \\
(n=3)\end{array}$ & $\begin{array}{l}1 \text { st } \\
(n=13)\end{array}$ & $\begin{array}{l}\text { 2nd } \\
(n=4)\end{array}$ \\
\hline \multicolumn{5}{|l|}{ Age, years } \\
\hline Median & 51.5 & 51.0 & 54.0 & 67.5 \\
\hline 25th percentile & 43.5 & 47.0 & 46.5 & 47.5 \\
\hline 75th percentile & 70.8 & 52.0 & 63.5 & 84.5 \\
\hline \multicolumn{5}{|l|}{$\mathrm{BMI}, \mathrm{kg} / \mathrm{m}^{2}$} \\
\hline Median & 25.5 & 22.8 & 26.4 & 26.4 \\
\hline 25th percentile & 22.7 & 22.7 & 23.7 & 23.0 \\
\hline 75th percentile & 28.7 & 22.8 & 32.6 & 39.6 \\
\hline \multicolumn{5}{|l|}{ Smoking, $n(\%)$} \\
\hline Actual/former smoker* & $4(33)$ & $1(33)$ & $4(31)$ & $1(25)$ \\
\hline Unknown & 8 & 2 & 9 & 3 \\
\hline \multicolumn{5}{|l|}{ Preoperative irradiation, $n(\%)$} \\
\hline Irradiated & $1(8)$ & $0(0)$ & $2(15)$ & $0(0)$ \\
\hline \multicolumn{5}{|l|}{ Comorbidity, n (\%) } \\
\hline Diabetes & $2(17)$ & $0(0)$ & $2(15)$ & $1(25)$ \\
\hline Hypertension & $4(33)$ & $1(33)$ & $2(15)$ & $2(50)$ \\
\hline \multicolumn{5}{|l|}{ Previous repair(s), $n$ (\%) } \\
\hline None & $9(75)$ & & $7(54)$ & \\
\hline One & $3(25)$ & & $6(46)$ & \\
\hline
\end{tabular}

No significant differences were found using logistic regression within these predictive factors. WVaF, vesico-vaginal fistula. ${ }^{*}$ Smoking not further divided based on packyears.
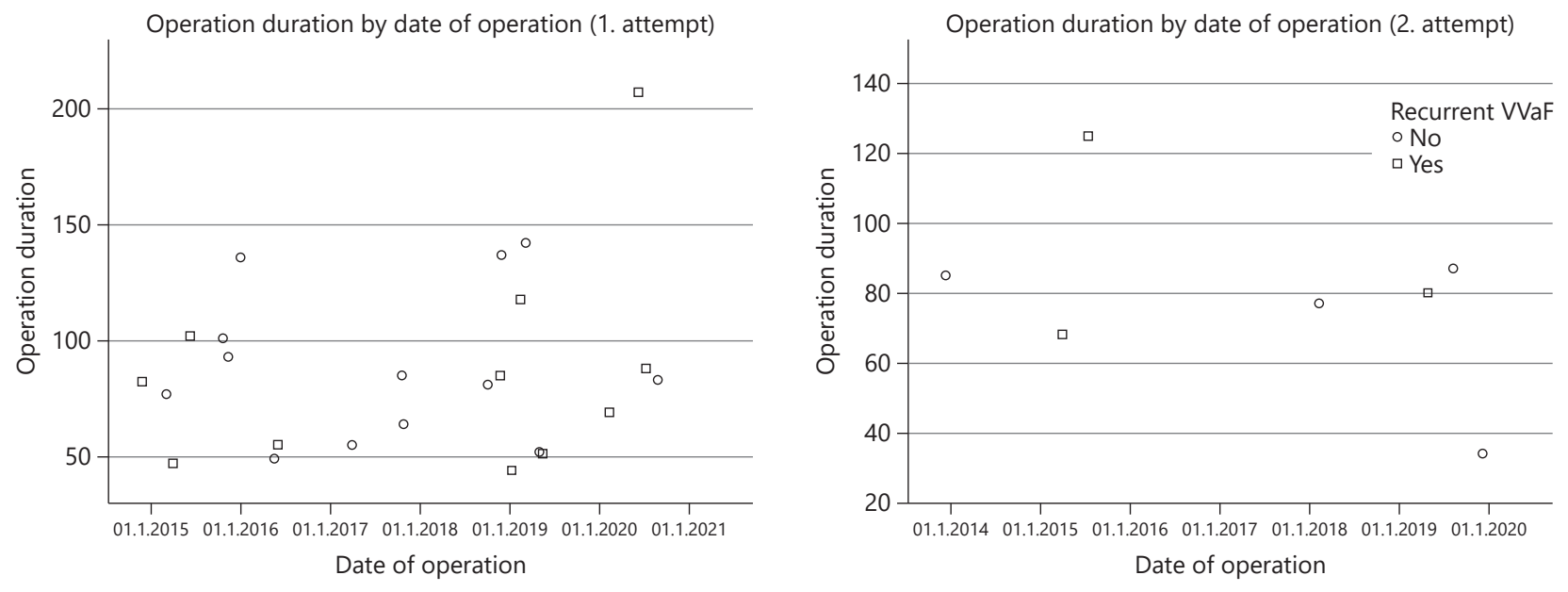

Fig. 1. Operation duration projected by the date of operation. VVaF, vesico-vaginal fistula.

who underwent surgery. If all patients who did not undergo a second attempt were taken into account with second attempt success rate, $79 \%$ of the VVaFs would have been successfully closed. One study found a success rate of $83 \%$ in 2 attempts, with the mentioned etiologies almost similar to our series [6]. Another study with high success rates was analyzed [7]. These studies included both patients with a transvaginal (with or without Mar- 
tius flap) and a transvesical approach. Therefore, these success rates are not suitable for comparison. In comparison with the success rates ranging from $75 \%$ to $100 \%$ in Pakistan [8], the transvaginal procedures included in this study were less successful. This is most likely due to the difference in incidence and etiology. The difference in etiology also creates a difference in fistula characteristics, which makes comparisons invalid.

Five patients had a cystography that showed leakage, and the catheter remained in situ for an extended period of time to support healing without success. The effect of the catheter remaining in situ therefore seems limited. One can even question the added value of cystography after surgery in this respect.

Most patients in this series with a former closed fistula shown on cystography had complaints of a recurrent fistula within 127 days. The timing of the onset of complaints might be linked toward the wound healing process. Wounds continue to undergo remodeling and maturation for several months [9]. Probably, this remodeling phase of wound healing determines whether scarring will occur or the fistula will reoccur. Recurrent fistulae with a previously closed cystography that occur within 4 months might be caused by insufficient wound remodeling and/ or scar formation. All kind of factors can be imagined to influence this remodeling process negatively like a small bladder capacity, former bladder radiation, and high intravesical pressure influence.

Smoking was not a predictive factor for success in our series. We found that a predicting parameter for success was a previous repair of a $\mathrm{VVaF}$ elsewhere, before being admitted to our hospital. This might be coincidental, but at least a previous transvaginal approach elsewhere is not a contraindication for a second transvaginal attempt. This is also observed in the success rates within this series that remained approximately the same for the first and second transvaginal attempt.

Procedures with a prolonged duration might have a higher chance of being unsuccessful. However, there is not a specific surgery time that indicates whether a procedure will be unsuccessful. Most procedures were performed by the same urologist, and there was no difference in recurrence rate over time or learning curve reflected in surgery time.

\section{Limitations}

The aim of this study was to determine the outcome of surgically treated $\mathrm{VVaFs}$ using transvaginal approach with a Latzko technique. This selection makes it difficult to compare with other published results of different ap- proaches. The authors would like to encourage others to publish their results per type of the surgical procedure instead of a series with a mixture of types.

The prevalence of VVaF surgery is low. Within this study, only a relatively small group of patients were included. This amount of cases makes it difficult to find statistically significant differences within groups and to find statistically significant predictive factors for the outcome of the VVaF operation.

\section{Recommendations and Further Research}

Further research should be with a higher inclusion of patients so that comparison is possible between different approaches and different groups, and statistically significant predictive factors for the outcome of the $\mathrm{VVaF}$ operation can be found. Robot-assisted surgery seems to provide minimal morbidity and good results [10]. Specific fistula characteristics might be more suitable for each procedure. Comparison of both robot-assisted and transvaginally approach, both minimal invasive techniques, is therefore recommended to assess which one is the most appropriate for different types/locations of $\mathrm{VVaF}$. With few minor complications noted within this cohort, the transvaginal surgical intervention with a Latzko technique remains a good treatment option for VVaFs. The effect of the catheter remaining in situ seems limited, and the cystography 2 weeks after surgery seems of limited added value to predict whether or not the catheter should remain in situ to support healing of the $\mathrm{VVaF}$. This study shows that a second attempt in closing the fistula with a transvaginal approach is useful, and a previous transvaginal attempt is not a contraindication for a second transvaginal attempt in closing the VVaF surgically.

\section{Statement of Ethics}

It was confirmed by the Ethics Committee of the Radboudumc that no approval of the study was needed (File No. 2020-6842). Informed consent was not required according to the law and regulations in the Netherlands. Therefore, no informed consent was obtained from the patients.

\section{Conflict of Interest Statement}

The authors have no conflicts of interest to declare.

\section{Funding Sources}

No research funding was received. 


\section{Author Contributions}

Jorrit Colenbrander contributed to project development, data collection, data analysis, and manuscript writing. John Heesakkers contributed to manuscript writing/editing. Frank Martens contributed to project development and manuscript writing/editing.

\section{Data Availability Statement}

All data generated or analyzed during this study are included in this article and its online supplementary material (for all online suppl. material, see www.karger.com/doi/10.1159/000519369). Further enquiries can be directed to the corresponding author.

\section{References}

1 Medina LG, Hernandez A, Sevilla C, Cacciamani GE, Winter M, Ashrafi A, et al. Robotic uterine-sparing vesicovaginal fistula repair. Int Urogynecol J. 2018;29(12):18457.

2 Hillary CJ, Osman NI, Hilton P, Chapple CR. The aetiology, treatment, and outcome of urogenital fistulae managed in well- and lowresourced countries: a systematic review. Eur Urol. 2016;70(3):478-92.

3 El-Azab AS, Abolella HA, Farouk M. Update on vesicovaginal fistula: a systematic review. Arab J Urol. 2019;17(1):61-8.
4 Fujisaki A, Kinjo M, Shimoinaba M, Honda S, Yoshimura Y. An evaluation of the impact of post-hysterectomy vesicovaginal fistula repair on the mental health of patients in a developed country. Int Urogynecol J. 2020 Jul; 31(7):1371-5.

5 Rajaian S, Pragatheeswarane M, Panda A. Vesicovaginal fistula: review and recent trends. Indian J Urol. 2019;35(4):250-8.

6 Milicevic S, Krivokuca V, Ecim-Zlojutro V, Jakovljevic B. Treatment of vesicovaginal fistulas: an experience of 30 cases. Med Arch. 2013;67(4):266-9.
7 Wahab F, Nasir A, Manan F. Outcome of VVF repair without omental interposition. J Pak Med Assoc. 2016;66(5):590-2.

8 Mubeen RM, Naheed F, Anwar K. Management of vesicovaginal fistulae in urological context. J Coll Physicians Surg Pak. 2007; $17(1): 28-31$.

9 Rodrigues M, Kosaric N, Bonham CA, Gurtner GC. Wound healing: a cellular perspective. Physiol Rev. 2019;99(1):665-706.

10 Antonelli A, Veccia A, Morena T, Furlan M, Peroni A, Simeone C. Robot-assisted vesicovaginal fistula repair: technical nuances. Int Braz J Urol. 2021 Mar;47(2):684-5. 